\title{
Esophageal perforation in eosinophilic esophagitis: five cases in children
}

\section{(ㄷ)(1)}

Authors

Camille Donnet ${ }^{1}$, Sylvie Destombe ${ }^{1}$, Alain Lachaux ${ }^{2}$, Laurent Michaud ${ }^{3}$, Valérie Triolo ${ }^{4}$, Sophie Heissat ${ }^{2}$, Jean-Louis Stephan ${ }^{1}$, Hugues Patural ${ }^{5}$

Institutions

1 Department of Pediatric Medicine, University Hospital of Saint-Étienne, Saint-Étienne, France

2 Department of Pediatric Hepatology and gastroenterology, Hospices Civils de Lyon, University C Bernard, Lyon, France

3 Department of Pediatric Hepatology and gastroenterology, University Hospital of Lille, Lille, France

4 Department of Pediatric Medicine, University Hospital of Nice, Nice, France

5 Intensive Care Unit, Department of Pediatric Medicine, University Hospital of Saint-Étienne, Saint-Etienne, France

submitted 19.2.2018

ccepted after revision 13.3.2018

Bibliography

DOI https://doi.org/10.1055/a-0914-2711 |

Endoscopy International Open 2020; 08: E830-E833

(c) Georg Thieme Verlag KG Stuttgart · New York eISSN 2196-9736
Corresponding author

Camille Donnet, Centre Hospitalier Universitaire de Saint-

Etienne - Service de Réanimation Pédiatrique et

Néonatologie, F 42055 Saint-Etienne Cedex 2 Saint-Etienne 42005, France

Fax: +33477828454

cam.donnet@gmail.com

\section{ABSTRACT}

Background and study aims Eosinophilic esophagitis (EoE) is a chronic immune disease with increasing incidence. It is clinically defined by symptoms of esophageal dysfunction and histologically by eosinophilic polynuclear cell infiltration of the esophageal mucosa. Symptoms are not specific and include gastroesophageal reflux disease (GERD), dysphagia, vomiting or dietary blockages. Chronic inflammation of the mucosa may lead to narrowing of the esophageal lumen responsible for impactions. Extraction procedures can be complicated by dissection and perforation. Rare spontaneous ruptures of the esophagus known as Boerhaave syndrome are also possible. We report five cases of esophageal perforation in children with EoE, three with spontaneous rupture and two after an endoscopic procedure. The evolution was favorable under medical treatment.

\section{Introduction}

Eosinophilic esophagitis (EoE) is defined as an immune and allergic chronic inflammatory disease characterized by symptoms of esophageal dysfunction. Symptoms in children are not specific and include signs of gastroesophageal reflux (GERD), vomiting, dysphagia, sensations of food blockage or real food impactions requiring emergency endoscopic extraction [1]. The main complications are esophageal stenosis and food impactions [1, 2]. Perforations and esophageal dissections remain exceptional. They can be spontaneous (also called Boerhaave syndrome) or secondary to an endoscopic procedure [3]. Only four cases of esophageal perforation related to EoE have been reported separately in children [3-6]. Here, we describe five pediatric cases of esophageal perforations related to an EoE collected through a survey among the Francophone Group of Hepatology, Gastroenterology and Pediatric Nutrition members.

\section{Patients and results}

Five cases of esophageal perforation with an EoE were identified in various French pediatric departments including three boys and two girls aged 2 to 17 . No children had been diagnosed with EoE prior to perforation. A history of atopy (asthma, allergic rhinitis) occurred in three children. One child had a history of atresia of the esophagus. A second child had complicated cirrhosis with esophageal varices secondary to histiocytosis $\mathrm{X}$ with liver injury. Three cases were spontaneous perforations follow- 


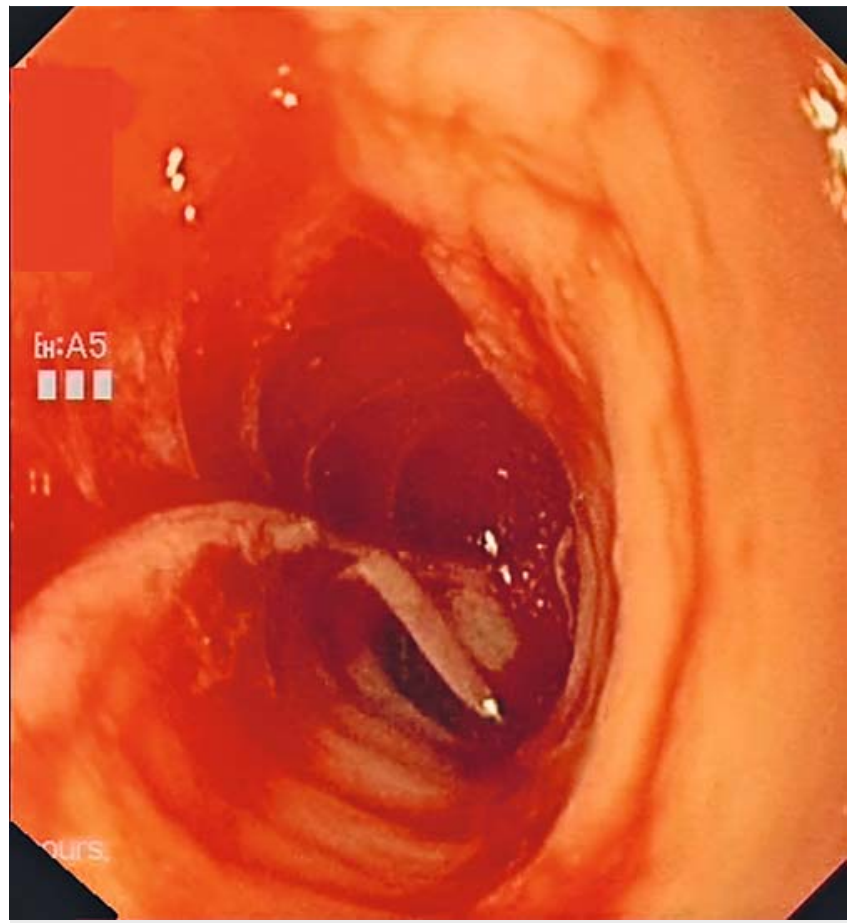

- Fig. 1 Gastroduodenal endoscopy (case 5) showing esophageal dissection with dilacerations of the mucosa and the submucosa.

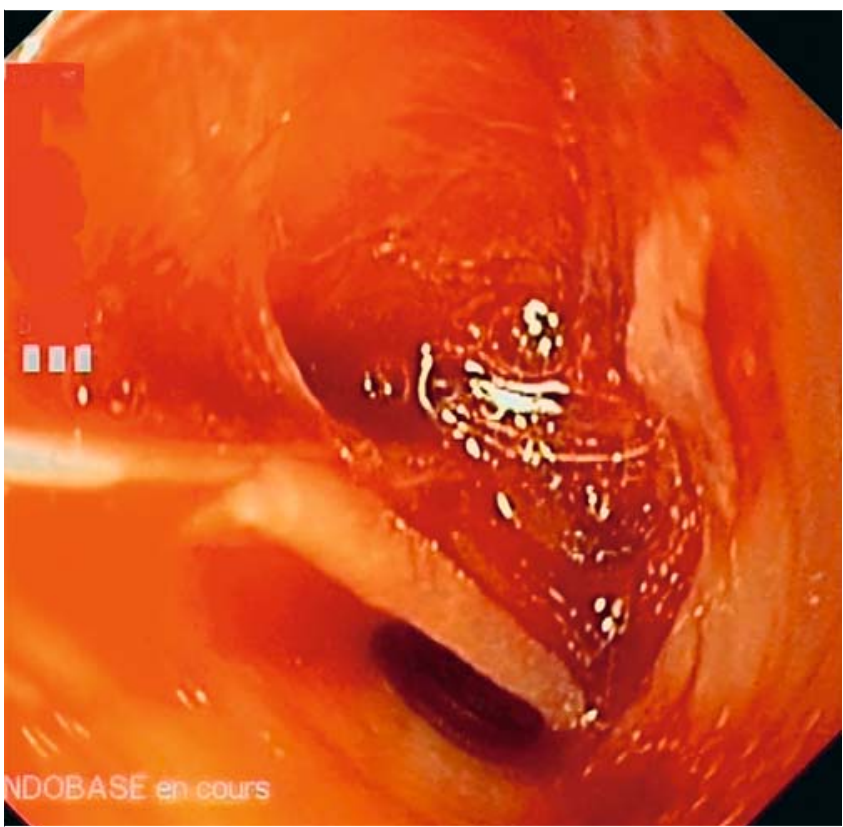

- Fig. 2 Gastroduodenal endoscopy (case 5) showing esophageal dissection with dilacerations of the mucosa and the submucosa.

ing food impaction and two cases were perforations during an endoscopic process. The three children with spontaneous perforation consulted the emergency department for sudden thoracic pain with vomiting, following a food blockage. One child also had hematemesis with fever. The other two cases of perforation occurred during gastroduodenal fibroscopy program-

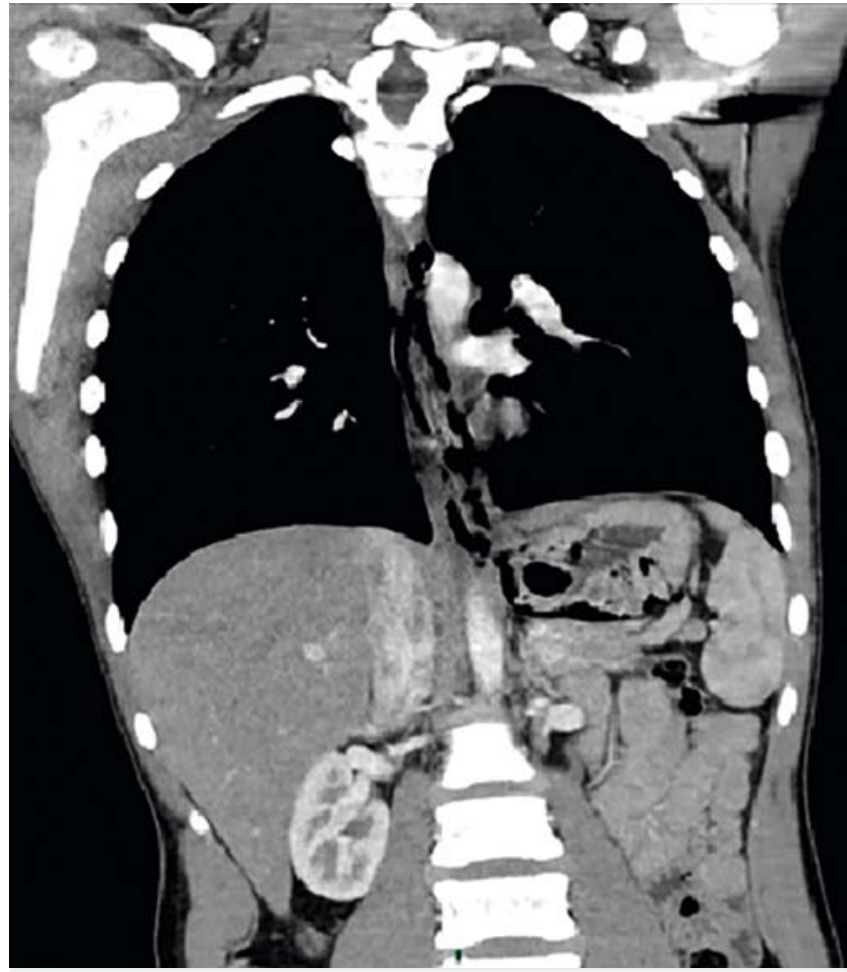

-Fig. 3 Thoracic-abdominal CT (case 1) showing the esophageal perforation with presence of pneumomediastinum.

med for control and dilation of esophageal stenosis in esophageal atresia and for control of esophageal varices in cirrhosis.

These two perforations occurred during the overpass of an esophageal stenosis. One child presented a respiratory distress syndrome secondary to endoscopic procedure ( $\bullet$ Fig.1, - Fig. 2). A chest scan was performed for four children. The only child who did not have chest computed tomography (CT) was one of the cases of perforation that occurred during endoscopy and had a simple chest $x$-ray. In all cases, chest CT showed pneumomediastinum associated with cervicothoracic effusion ( $\triangleright$ Fig.3). Fibroscopy performed at or near the episode showed signs of suggestive EoE (linear streaks, whitish deposits, trachealized appearance of the esophagus) and the biopsy confirmed the diagnosis with more than 15 eosinophilic polynuclear per field at high magnification. The treatment was conservative for all five children with intravenous antibiotic therapy combined with a proton pump inhibitor. Enteral feeding was performed for a few days with a short period of fasting. The evolution was simple for the five children. Treatment of the EoE established after confirmation of the diagnosis was variable. Some children were treated with corticosteroids (budesonide), others were on an eviction diet.

Data for the five cases are summarized in $>$ Table 1 .

\section{Discussion}

EoE is an immune and allergic chronic disease responsible for functional disorders of the esophagus such as dysphagia, GERD, and oral disorders. The main complications are food im- 
- Table1 Data on five cases of esophageal perforation in eosinophilic esophagitis.

\begin{tabular}{|c|c|c|c|c|c|}
\hline & Case 1 & Case 2 & Case 3 & Case 4 & Case 5 \\
\hline $\begin{array}{l}\text { Sex/age } \\
\text { (years) }\end{array}$ & Male/14 yr & Female/9 yr & Male/12 yr & Female/2 yr & Male/17 yr \\
\hline $\begin{array}{l}\text { Prior diagnosis } \\
\text { of eosinophilic } \\
\text { esophagitis }\end{array}$ & No & No & No & No & No \\
\hline $\begin{array}{l}\text { Clinical } \\
\text { symptoms }\end{array}$ & $\begin{array}{l}\text { Retrosternal pain, } \\
\text { vomiting, hematem- } \\
\text { esis }\end{array}$ & $\begin{array}{l}\text { Chest pain, gastro- } \\
\text { esophageal reflux, } \\
\text { fever }\end{array}$ & $\begin{array}{l}\text { Retrosternal pain, } \\
\text { vomiting, dysphagia, }\end{array}$ & $\begin{array}{l}\text { Acute respiratory } \\
\text { distress }\end{array}$ & $\begin{array}{l}\text { Dissection during } \\
\text { endoscopic crossing } \\
\text { of a stenosis }\end{array}$ \\
\hline Complication & $\begin{array}{l}\text { Impaction and spon- } \\
\text { taneous perforation }\end{array}$ & $\begin{array}{l}\text { Impaction and spon- } \\
\text { taneous perforation }\end{array}$ & $\begin{array}{l}\text { Impaction and spon- } \\
\text { taneous perforation }\end{array}$ & $\begin{array}{l}\text { Perforation during } \\
\text { endoscopic dilation } \\
\text { of stenosis }\end{array}$ & \\
\hline Chest CT & $\begin{array}{l}\text { Pneumomediasti- } \\
\text { num, pneumoperitis, } \\
\text { esophageal fissure }\end{array}$ & $\begin{array}{l}\text { Esophageal perfora- } \\
\text { tion, peri-esopha- } \\
\text { geal fluid collection }\end{array}$ & $\begin{array}{l}\text { Pneumomediasti- } \\
\text { num, cervico-thorac- } \\
\text { ic effusion }\end{array}$ & $\begin{array}{l}\text { Pneumomediasti- } \\
\text { num }\end{array}$ & Endoscopic diagnosis \\
\hline $\begin{array}{l}\text { Endoscopic } \\
\text { data }\end{array}$ & $\begin{array}{l}\text { Trachealized appear- } \\
\text { ance, longitudinal } \\
\text { streaks, whitish de- } \\
\text { posits }\end{array}$ & $\begin{array}{l}\text { Normal mucosa, re- } \\
\text { sistance to passage } \\
\text { of endoscopy }\end{array}$ & $\begin{array}{l}\text { Trachealized appear- } \\
\text { ance, longitudinal } \\
\text { streaks, whitish de- } \\
\text { posits }\end{array}$ & $\begin{array}{l}\text { Esophageal stenosis, } \\
\text { whitish granulations }\end{array}$ & $\begin{array}{l}\text { Trachealized appear- } \\
\text { ance, esophageal } \\
\text { stenosis }\end{array}$ \\
\hline Treatment & $\begin{array}{l}\text { Conservative man- } \\
\text { agement }\end{array}$ & $\begin{array}{l}\text { Conservative man- } \\
\text { agement }\end{array}$ & $\begin{array}{l}\text { Conservative man- } \\
\text { agement }\end{array}$ & $\begin{array}{l}\text { Conservative man- } \\
\text { agement }\end{array}$ & $\begin{array}{l}\text { Conservative man- } \\
\text { agement }\end{array}$ \\
\hline
\end{tabular}

pactions and esophageal stenosis. We have described five pediatric cases of perforation but dissections and perforations of the esophagus remain exceptional because prevalence of EoE in children is estimated at 29.5 cases per 100,000 in Western countries [7]. In 2008, Straumann et al. [8] reported a single case of spontaneous esophageal rupture out of 251 adult and adolescent cases of EoE over 18 years. In our description, three of five reported cases corresponded to spontaneous rupture of the esophagus after vomiting efforts following a food impaction. These spontaneous ruptures, also known as Boerhaave syndrome, have been described in two other pediatric cases $[4,5]$.

Boerhaave syndrome was first described in 1724 by Herman Boerhaave about an adult who died from an esophageal rupture after vomiting following a copious meal. The clinical triad includes vomiting, retrosternal pain and subcutaneous emphysema. Imaging classically identifies pneumomediastinum and pneumothorax. In children, it is also described in the context of vomiting or high obstruction of the esophagus by ingestion of a foreign body (FB) [3]. In EoE, we find the same mechanism of vomiting efforts to evacuate food FB impacted on an inflammatory esophageal mucosa. Food impactions are recurrent and correspond to $10 \%$ of esophageal FB in children [9].

Retrospective studies in children and adults [10] suggest that approximately half of food impactions requiring endoscopic extraction are secondary to EoE. They are mainly induced by spasms or esophageal stenosis and are predominant in adults or adolescents and signal the chronicity of the disease. In our case series, esophageal perforation revealed EoE in all five cases. The other cases of spontaneous perforations de- scribed in the literature also support the diagnosis. This points out the delayed diagnosis that still exists in EoE, partly explained by lack of knowledge of the disease but also by the adaptive mechanisms initiated by dysphagic children.

Our series also describes two cases of esophageal perforation that occurred during or immediately after gastroduodenal fibroscopy. The literature reports few perforations induced by an endoscopic process. Strauman et al [8] described only 2 cases of perforation in 134 endoscopic extractions of food impactions. These two cases, however, corresponded to $20 \%$ $(2 / 10)$ of the cases having benefited from a rigid tube extraction. These descriptions, although rare, therefore require great caution when performing endoscopies and preferential use of a flexible fibroscope. Complications secondary to dilatation of esophageal stenosis in EoE are also very rare. In one study [1], the perforation rate was evaluated at $0.8 \%$ with only three perforations in 404 patients out of a total of 839 esophageal dilatations. In EoE, dilatation can result in a long and immediate improvement in symptoms of dysphagia in an adult [11]. On the other hand, it has been demonstrated in children that esophageal stenoses are often reversible with treatment (corticosteroid or diet eviction), which would limit indications for dilatation [9].

In our series, the case of perforation during dilatation for stenosis is described in a child with a history of esophageal atresia. Several publications report cases of EoE in patients with esophageal atresia [12]. Dysphagia is a common symptom in these patients and is often credited to recurrent stenosis, esophageal motility disorders or presence of GERD. The different observations all suggest that diagnosis of EoE should be 
suggested and investigated in patients with esophageal atresia and GERD or dysphagia, especially if the symptoms persist despite well-managed treatment [13].

An interesting topic raised by our series is the immediate positive evolution of the five cases without any endoscopic or surgical treatment. Digestive rest associated with antibiotic therapy was sufficient even in cases with a mediastinal collection. In the two other pediatric cases reported in the literature, one patient underwent the same treatment with a good evolution [5]; the second presented a false mucous pathway 20 days after the dissection treated by endoscopic section [4]. In adults, care is quite variable. Transient prostheses or clips [14], surgical treatments with mediastinal drainage or laparotomy with perforation suture or even partial esophagectomy have been reported [15]. No deaths were reported following a perforation complication.

\section{Conclusion}

The main complications of EoE are food impactions. Ruptures and perforation of the esophagus in children with EoE are rare. They can be caused by an endoscopic procedure or spontaneously during food impaction. The evolution is generally favorable under medical treatment.

\section{Competing interests}

The authors declare that they have no conflict of interest.

\section{References}

[1] Liacouras CA, Furuta GT, Hirano I et al. Eosinophilic esophagitis: updated consensus recommendations for children and adults. J Allergy Clin Immunol 2011; 128: 3-20.e6

[2] Furuta GT, Katzka DA. Eosinophilic Esophagitis. N Engl J Med 2015; 373: $1640-1648$
[3] Antonis JH, Poeze M, Van Heurn LW. Boerhaave's syndrome in children: a case report and review of the literature. J Pediatr Surg 2006; 41: $1620-1623$

[4] Sgrò A, Betalli P, Battaglia G et al. An unusual complication of eosinophilic esophagitis in an adolescent: intramural esophageal dissection. Endoscopy 2012; 44: E419-E420

[5] Giles H, Smith L, Tolosa D et al. Esophagitis: a rare cause of esophageal rupture in children. The American Surgeon 2008; 74: 750 - 752

[6] Robles-Medranda C, Villard F, Bouvier R et al. Spontaneous esophageal perforation in eosinophilic esophagitis in children. Endoscopy 2008; 40: E171

[7] Arias Á, Pérez-Martínez I, Tenías JM et al. Systematic review with meta-analysis: the incidence and prevalence of eosinophilic oesophagitis in children and adults in population-based studies. Aliment Pharmacol Ther 2016; 43: 3-15

[8] Straumann A, Bussmann C, Zuber M et al. Eosinophilic esophagitis: analysis of food impaction and perforation in 251 adolescent and adult patients. Clin Gastroenterol Hepatol 2008; 6: 598-600

[9] Muir A, Merves J, Liacouras CA. Role of endoscopy in diagnosis and management of pediatric eosinophilic esophagitis. Gastrointest Endosc Clin N Am 2016; 26: 187-200

[10] Hiremath GS, Hameed F, Pacheco A et al. Esophageal food impaction and eosinophilic esophagitis: a retrospective study, Systematic review, and meta-analysis. Digest Dis Sci 2015; 60: 3181 - 3193

[11] Schoepfer AM, Gonsalves N, Bussmann C et al. Esophageal dilation in eosinophilic esophagitis: effectiveness, safety, and impact on the underlying inflammation. Am J Gastroenterol 2010; 105: 1062 - 1070

[12] Yamada Y, Nishi A, Kato M et al. Esophagitis with eosinophil infiltration associated with congenital esophageal atresia and stenosis. Int Arch Allergy Immunol 2013; 161: 159-163

[13] Kassabian S, Baez-Socorro V, Sferra T et al. Eosinophilic esophagitis in patients with esophageal atresia and chronic dysphagia. World J Gastroenterol 2014; 20: $18038-18043$

[14] Jacobs JW Jr, Fatima H, Cote GA et al. Stenting of esophageal perforation in the setting of eosinophilic esophagitis. Digest Dis Sci 2015; 60: $1098-1100$

[15] Jackson WE, Mehendiratta V, Palazzo J et al. Boerhaave's syndrome as an initial presentation of eosinophilic esophagitis: a case series. Annals Gastroenterol 2013; 26.2: 166-169 